\title{
Motor and Sensory Function as a Predictor of Respiratory Function Associated With Ventilator Weaning After High Cervical Cord Injury
}

Tae Wan Kim, $\mathrm{MD}^{1}$, Jung Hyun Yang, $\mathrm{MD}^{1}$, Sung Chul Huh, $\mathrm{MD}^{2}$, Bon Il Koo, $\mathrm{MD}^{2}$, Jin A Yoon, MD, $\mathrm{PhD}^{1}$, Je Sang Lee, $\mathrm{MD}^{1}$, Hyun-Yoon $\mathrm{Ko}, \mathrm{MD}, \mathrm{PhD}^{2}$, Yong Beom Shin, $\mathrm{MD}, \mathrm{PhD}^{1}$

\begin{abstract}
${ }^{1}$ Department of Rehabilitation Medicine, Pusan National University School of Medicine and Biomedical Research Institute, Pusan National University Hospital, Busan; ${ }^{2}$ Department of Rehabilitation Medicine, Pusan National University School of Medicine and Research Institute of Convergence for Biomedical Science and Technology,

Pusan National University Yangsan Hospital, Yangsan, Korea
\end{abstract}

\begin{abstract}
Objective To analyze the respiratory function of high cervical cord injury according to ventilator dependence and to examine the correlations between diaphragm movement found on fluoroscopy and sensory and motor functions.

Methods A total of 67 patients with high cervical spinal cord injury (SCI), admitted to our hospital were enrolled in the study. One rehabilitation physician performed sensory and motor examinations on all patients while each patient was in the supine position on the American Spinal Injury Association (ASIA) standard. In addition, fluoroscopic diaphragm movement studies and bedside spirometry were performed.

Results Bedside spirometry and diaphragm fluoroscopic tests were analyzed according to ventilator dependence. Forced vital capacity and maximal inspiratory pressure were significantly higher in the ventilator weaned group. Natural breathing during the fluoroscopic diaphragm examinations and ventilator weaning showed statistical significance with the movement on the right, while deep breathing showed statistical significance with the movement on both sides. Deep breathing movement has correlation with the C5 key muscle. Diaphragm movement has correlation with right C3 and bilateral C4 sensory functions.

Conclusion The present expansion study showed that, through simple bedside physical examinations, rehabilitation physicians could relatively easily predict diaphragm movement and respiratory function recovery, which showed significance with ventilator weaning in patients with high cervical SCI.
\end{abstract}

Keywords Spinal cord injuries, Cervical cord, Respiratory function tests, Physical examination

Received July 14, 2017; Accepted September 6, 2017

Corresponding author: Yong Beom Shin

Department of Rehabilitation Medicine, Pusan National University School of Medicine and Biomedical Research Institute, Pusan National University Hospital, 179 Gudeok-ro, Seo-gu, Busan 49241, Korea. Tel: +82-51-240-7485, Fax: +82-51-247-7485, E-mail: yi0314@gmail.com

ORCID: Tae Wan Kim (http://orcid.org/0000-0002-5418-9406); Jung Hyun Yang (http://orcid.org/0000-0002-8480-2187); Sung Chul Huh (http://orcid. org/0000-0002-7740-8050); Bon Il Koo (http://orcid.org/0000-0002-5142-2743); Jin A Yoon (http://orcid.org/0000-0001-5762-0559); Je Sang Lee (http:// orcid.org/0000-0001-6617-3113); Hyun-Yoon Ko (http://orcid.org/0000-0001-5506-7219); Yong Beom Shin (http://orcid.org/0000-0001-5026-1696).

(c) This is an open-access article distributed under the terms of the Creative Commons Attribution Non-Commercial License (http://creativecommons.org/ licenses/by-nc/4.0) which permits unrestricted noncommercial use, distribution, and reproduction in any medium, provided the original work is properly cited. Copyright (C) 2018 by Korean Academy of Rehabilitation Medicine 


\section{INTRODUCTION}

After experiencing a spinal cord injury (SCI), ventilator dependence is the main respiratory limitation patients encounter [1]. Especially in those who experience cervical cord injury, the level of neurological injury as it affects diaphragm function has an impact on this complication. In particular, when the diaphragm is innervated by the phrenic nerve at the $\mathrm{C} 4$, with contribution commonly seen from C3 and C5 [2], leading to diaphragm paralysis.

Approximately two-thirds of patients with acute SCI will experience respiratory complications requiring mechanical ventilation [3]. Among patients with high cervical cord injuries ( $\mathrm{C} 1$ to $\mathrm{C} 4)$, the incidence of ventilator dependence has finally been reported to be down to $40 \%$ [4]. As there are no definite cures for this type of paralysis; therefore, long-term mechanical ventilator use is inevitable. This can lead to various respiratory complications, which are the leading causes of death in patients with cervical cord injuries [5]. Thus, several previous studies of cervical cord injury patients have evaluated possible predictors for ventilator weaning. Oo et al. [6] demonstrated that patients with $\mathrm{C} 1$ to $\mathrm{C} 4 \mathrm{SCI}$, intact diaphragms, and forced vital capacity (FVC) of at least $17 \mathrm{~mL} / \mathrm{kg}$ were able to be weaned from the ventilator.

Since the diaphragm is the main major muscle involved in inspiration [7], Chiodo et al. [8] made a retrospective review of SCI patients with involvement from C2 to C6 and predicted that patients without motor unit recruitment of the hemidiaphragm or a moderate decrease in the recruitment of both diaphragms using needle electromyography (EMG) would be unable to be weaned off the ventilator. Diaphragm function can be examined using various tests. Fluoroscopy-based approaches are mainly used to examine diaphragm movement [8]. Diaphragmatic fluoroscopy provides a bilateral view of the diaphragm and assesses not only the qualitative features of the movement of the diaphragm but the quantitative features. In addition, diaphragmatic fluoroscopy can easily determine the presence of malformation and of diaphragm paralysis [9].

These major respiratory impairments are associated with interruptions of the descending bulbospinal respiratory pathway. Wicks and Menter [10] demonstrated that the level of patients' injuries influenced the rate of ventilator weaning. However, the relationship between dia- phragm movement and the motor and sensory functions around the injured segment has not been investigated $[11,12]$.

The specific objectives of the study were (1) to analyze the respiratory function of high cervical cord injuries according to ventilator dependence and (2) to examine the correlations between diaphragm movement found on fluoroscopy and sensory and motor functions evaluated through physical examinations, which can be relatively easily conducted at bedside by rehabilitation physicians.

\section{MATERIALS AND METHODS}

A total of 67 patients with high cervical SCI (56 male and 11 female; average age, $56.6 \pm 15.9$ years) who had been admitted to our hospital were enrolled in the study. Inclusion criteria were SCI patients with a neurologic level of injury of C2 to C5 by the American Spinal Injury Association (ASIA) standard, with or without ventilator care at the time of transfer to the Department of Rehabilitation from March 2013 to January 2017.

Patients with any of the following characteristics during their hospital stay were excluded from the study: hemodynamic instability, a cognitive impairment or sedative state, or a spinal shock state. All patients provided written informed consent prior to inclusion in the study. The study was approved by the Pusan National University Hospital Institutional Review Board (IRB No. 1710-008060).

A fluoroscopic diaphragm test was conducted on all patients. Bedside spirometry and experience of ventilator weaning were also evaluated in order to analyze the respiratory function of high cervical cord injury according to ventilator dependence. For each patient, a physical exam, a fluoroscopic examination, and bedside spirometry were attempted from the time they were transferred to the rehabilitation department, and ventilator weaning was attempted to discharge day. After confirming the statistical significance between the fluoroscopic diaphragm test results and those of the bedside motor/sensory examination, we assessed whether a motor/sensory examination can predict diaphragm movement, that is, respiratory function.

\section{Bedside physical examination}

While each patient was in the supine position, rehabili- 
tation doctors performed sensory and motor examinations under supervision. Patients were scored bilaterally according to the ASIA standard.

Regarding the C5 key muscle, three points were given for lifting against gravity, which was used as a cut-off to categorize patients into two groups. One group of patients scored 3 to 5 points, and the other scored zero to 2 points in C5 key muscle. With respect to the performances on the pin-prick test and light touch test, a score of 2 points was regarded as normal. Scores of zero to 1 point were regarded as indicating sensory impairment. The correlation with the ipsilateral diaphragm movement was examined using categorical variables.

\section{Fluoroscopic examination}

The patients were transported to a fluoroscopy room in the hospital on the same day as the physical examination, and a fluoroscopic diaphragm movement study was performed using a Toshiba Ultimax-i DREX-UI80 (Toshiba America Medical System Inc., Tustin, CA, USA). During the examination, 10 minutes after the ventilator was turned off, each patient was instructed to take three natural, deep breaths while in the supine position, and the maximum movement of the diaphragm was recorded (Fig. 1). In each phase of the test, the charge doctor watched the patients with care and told each to breathe without any effort or to breathe with maximum effort.

\section{Bedside spirometry}

To investigate the link between diaphragm movement and the respiratory function test, a bedside spirometry (COSMED, Rome, Italy) was conducted by a trained physical therapist who had received an education in the administration of the pulmonary function test, which is used to measure tidal volume (TV), force vital capacity (FVC), and maximal inspiratory pressure (MIP). TV refers to the lung volume, or the normal volume of air displaced between normal inhalation and exhalation. FVC is maximum amount of air a person can expel from the lungs after a maximum inhalation. MIP is the maximum pressure that can be generated against an occluded airway, an important and noninvasive index of diaphragm strength. The spirometry was repeated three times while the patient was in the supine position.

\section{Statistical analysis}

The quantitative traits were analyzed using a Wilcoxon rank-sum test, t-test, and linear regression, as appropriate. The p-values less than 0.05 were defined as statistically significant. Pearson correlation coefficient between diaphragm movement and bedside spirometry was calculated. All data were analyzed using IBM SPSS version 22 (IBM, Armonk, NY, USA).

\section{RESULTS}

Number and characteristics of patients, including sex, age, neurologic level of injury, and completeness (motor complete, A and B; motor incomplete, C and D), days from injury and ventilator weaning based on whether the patient was finally weaned from the ventilator are shown in Tables 1 and 2. As shown in Table 2, neurologic level of injury and motor completeness were not predictive factors for ventilator weaning at the time of discharge, and average of length of stay was $90.11 \pm 142.79$ days in ventilator weaned group and $133.67 \pm 209.34$ days in the
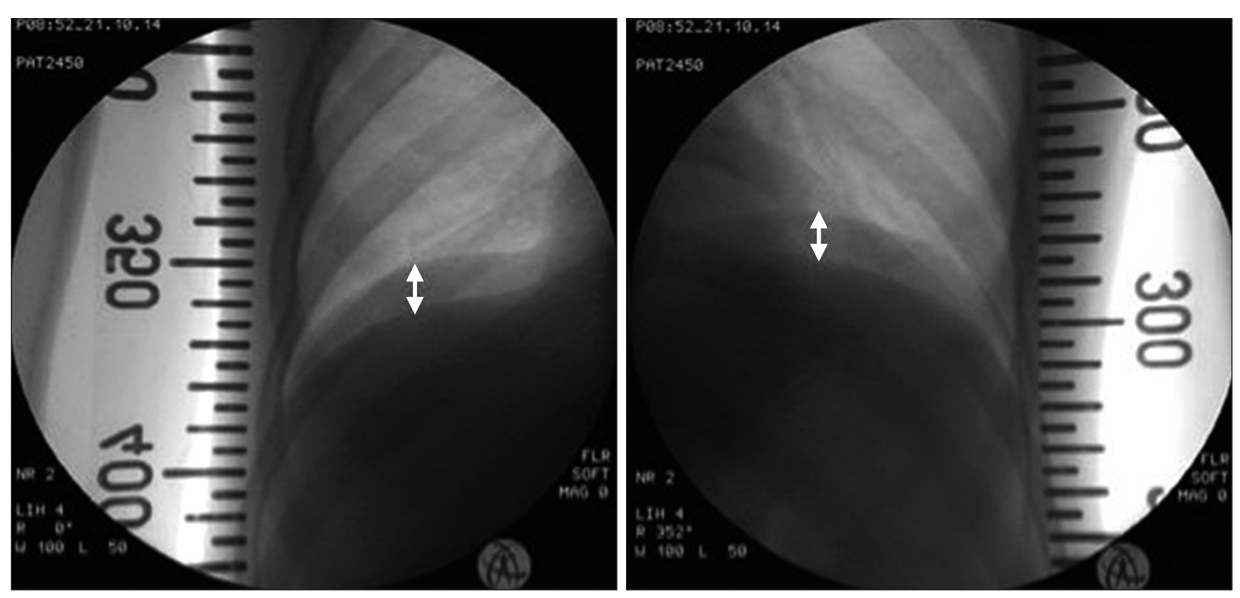

Fig. 1. Fluoroscopic diaphragm examination. 
Tae Wan Kim, et al.

Table 1. Demographic and clinical data of the patients

\begin{tabular}{|c|c|c|c|c|}
\hline & Ventilator weaned & Ventilator not weaned & Total & p-value \\
\hline Number of patients & $46(68.7)$ & $21(31.3)$ & $67(100)$ & 0.84 \\
\hline Men & $40(59.8)$ & $16(23.8)$ & $56(83.6)$ & \\
\hline Women & $6(9.0)$ & $5(7.4)$ & $11(16.4)$ & \\
\hline Age (yr) & $55.2 \pm 15.8$ & $59.7 \pm 16.4$ & $56.6 \pm 15.9$ & 0.12 \\
\hline Evaluation day from injury (day) & $26.68 \pm 128.91$ & $56.80 \pm 142.39$ & $36.98 \pm 152.28$ & $0.001^{*}$ \\
\hline Length of stay (day) & $90.11 \pm 142.79$ & $133.67 \pm 209.34$ & $99.45 \pm 161.26$ & \\
\hline Ventilator weaning (day) & $17.54 \pm 77.11$ & - & - & \\
\hline
\end{tabular}

Values are presented as number (\%) or mean \pm standard deviation.

${ }^{*} \mathrm{p}<0.05$.

Table 2. Correlation between neurologic level of injury and ventilator weaning

\begin{tabular}{|c|c|c|c|c|c|}
\hline & & $\begin{array}{c}\text { Ventilator } \\
\text { weaned }\end{array}$ & $\begin{array}{c}\text { Ventilator not } \\
\text { weaned }\end{array}$ & Total & p-value \\
\hline ASIA impairment scale & & & & & 0.64 \\
\hline A & Motor complete & $20(76.9)$ & $6(23.1)$ & $26(100)$ & \\
\hline B & Motor complete & $4(50)$ & $4(50)$ & $8(100)$ & \\
\hline $\mathrm{C}$ & Motor incomplete & $14(66.7)$ & $7(33.3)$ & $21(100)$ & \\
\hline $\mathrm{D}$ & Motor incomplete & $8(66.7)$ & $4(33.3)$ & $12(100)$ & \\
\hline Neurologic level of injury & & & & & 0.07 \\
\hline \multirow[t]{2}{*}{$\mathrm{C} 2$} & Motor complete & $0(0)$ & $1(100)$ & $1(100)$ & \\
\hline & Motor incomplete & $4(66.67)$ & $2(33.33)$ & $6(100)$ & \\
\hline \multirow[t]{2}{*}{ C3 } & Motor complete & $9(81.82)$ & $2(18.18)$ & $11(100)$ & \\
\hline & Motor incomplete & $4(80)$ & $1(20)$ & $5(100)$ & \\
\hline \multirow[t]{2}{*}{$\mathrm{C} 4$} & Motor complete & $14(77.78)$ & $4(22.22)$ & $18(100)$ & \\
\hline & Motor incomplete & $9(52.94)$ & $8(47.06)$ & $17(100)$ & \\
\hline \multirow[t]{2}{*}{ C5 } & Motor complete & $1(25)$ & $3(75)$ & $4(100)$ & \\
\hline & Motor incomplete & $5(100)$ & $0(0)$ & $5(100)$ & \\
\hline
\end{tabular}

Values are presented as number (\%).

ASIA, American Spinal Injury Association.

group not weaned from the ventilator. Results of bedside spirometry and diaphragm fluoroscopic tests are shown in Table 3. FVC in the ventilator weaned and not weaned group were $2.68 \pm 6.99 \mathrm{~L}$ and $1.13 \pm 0.83 \mathrm{~L}$, respectively, with statistical significance. MIP in the ventilator weaned and not weaned group were $50.02 \pm 43.13 \mathrm{cmH}_{2} \mathrm{O}$ and $30.90 \pm 33.72 \mathrm{cmH}_{2} \mathrm{O}$, respectively, with statistical significance. Natural breathing during the fluoroscopic diaphragm examination and ventilator weaning showed a statistical significance with movement on the right, while deep breathing showed statistical significance with movement on both sides.

There was significantly more diaphragm movement during deep breathing in the group of patients with a score greater than three on the manual muscle test for the C5 key muscle, compared with the group of patients scoring less than 3 (Table 4). There was significantly more diaphragm movement during deep breathing in the group of patients with intact right C3 and bilateral C4 sensory functions based on the pin-prick test. Only the right $\mathrm{C} 4$ dermatome was significant for the light touch test (Table 5).

\section{DISCUSSION}

In our study, the neurological level of injury and motor 
Table 3. Bedside spirometry and diaphragm test of the patients

\begin{tabular}{|lccc|}
\hline & Ventilator weaned & Ventilator not weaned & p-value \\
\hline Bedside spirometer & & & \\
\hline TV $(\mathrm{L})$ & $1.64 \pm 2.36$ & $0.69 \pm 1.20$ & 0.31 \\
\hline FVC (L) & $2.68 \pm 6.99$ & $1.13 \pm 0.83$ & $0.002^{*}$ \\
\hline MIP $\left(\mathrm{cmH}_{2} \mathrm{O}\right)$ & $50.02 \pm 43.13$ & $30.90 \pm 33.72$ & $0.001^{*}$ \\
\hline Diaphragm test & & & \\
\hline Right natural breathing & $3.00 \pm 1.84$ & $1.59 \pm 0.81$ & $0.005^{*}$ \\
\hline Left deep breathing & $4.79 \pm 1.99$ & $3.13 \pm 1.77$ & $0.011^{*}$ \\
\hline Right deep breathing & $5.13 \pm 2.34$ & $2.91 \pm 1.93$ & $0.003^{*}$ \\
\hline
\end{tabular}

Values are presented as mean \pm 2 standard deviation.

TV, tidal volume; FVC, forced vital capacity; MIP, maximal inspiratory pressure.

${ }^{*} \mathrm{p}<0.05$.

Table 4. Correlation between C5 key muscle strength and diaphragm movement during deep breathing

\begin{tabular}{ccccc}
\hline & \multicolumn{3}{c}{ Diaphragm movement (cm) } \\
\cline { 2 - 5 } & Right & p-value & Left & p-value \\
\hline C5 motor & \multicolumn{3}{c}{$0.002^{*}$} \\
$\geq 3(n=29)$ & $6.3 \pm 0.8$ & & $5.1 \pm 1.6$ & \\
$<3(n=38)$ & $3.0 \pm 2.1$ & & $3.1 \pm 1.8$ & \\
\hline
\end{tabular}

Values are presented as mean \pm 2 standard deviation. ${ }^{*} \mathrm{p}<0.05$.

completeness of injury had no significant correlation with patients' ventilator weaning at the point of discharge. We demonstrated that the extent of diaphragm movement during deep breathing, as assessed via fluoroscopic examination, effectively assesses pulmonary function in patients with high SCI, and this was significantly correlated with patients' ventilator weaning. In addition, diaphragm movement significantly increased in the group of patients with a motor function score greater than 3 points in the $\mathrm{C} 5$ key muscle and more than 2 points in the C4 dermatome pin-prick test. As fluoroscopic diaphragm examination is not routinely performed in all hospitals, a simple bedside examination could be an effective tool used to predict diaphragm movement and respiratory function recovery.

Predicting patient prognosis and appropriate pulmonary management are very important when treating patients who have experienced cervical SCI. Scanlon et al. [13] described that lung function reduction or decreased lung compliance occurs within a month of injury and does not change during the year thereafter. A paradoxical response of the diaphragm (i.e., inward movement of
Table 5. Correlation between pin-prick and light touch sense and diaphragm movement during deep breathing

\begin{tabular}{|c|c|c|c|c|}
\hline & \multicolumn{4}{|c|}{ Diaphragm movement $(\mathrm{cm})$} \\
\hline & Right & p-value & Left & p-value \\
\hline \multicolumn{5}{|l|}{ Pin-prick } \\
\hline C3 sensory & & $0.034^{*}$ & & 0.654 \\
\hline $2(n=57)$ & $4.7 \pm 2.4$ & & $4.4 \pm 2.1$ & \\
\hline 0 or $1(n=10)$ & $2.4 \pm 1.6$ & & $3.9 \pm 1.7$ & \\
\hline C4 sensory & & $0.001^{*}$ & & $0.044^{*}$ \\
\hline $2(\mathrm{n}=44)$ & $5.3 \pm 2.4$ & & $4.8 \pm 2.0$ & \\
\hline 0 or $1(n=23)$ & $2.9 \pm 1.5$ & & $3.3 \pm 1.6$ & \\
\hline \multicolumn{5}{|l|}{ Light touch } \\
\hline C4 sensory & & $0.011^{*}$ & & 0.234 \\
\hline $2(\mathrm{n}=46)$ & $5.0 \pm 2.4$ & & $4.6 \pm 2.1$ & \\
\hline 0 or $1(n=21)$ & $3.1 \pm 1.8$ & & $3.5 \pm 1.6$ & \\
\hline
\end{tabular}

Values are presented as mean \pm 2 standard deviation. ${ }^{*} \mathrm{p}<0.05$.

upper anterior rib cage during inspiration) is caused by the distortion of the respiratory system. This leads to respiratory muscle fatigue and various pulmonary complications during an acute phase [14,15]. Accordingly, after acute SCI it is critical to predict the recovery of pulmonary function and determine an appropriate approach to respiratory rehabilitation while the patient is maintained on a ventilator or after he or she is weaned off the ventilator. It is meaningful to monitor motor recovery relevant to pulmonary function recovery, since pulmonary function is highly associated with the timing of a recovery from muscle flaccidity [2]. However, early predictors of ventilator dependency after high cervical cord injury have not been clearly established; therefore, we tried to describe 
the association between pulmonary function and physical examination in our study.

In our study, exact diaphragm movement was assessed by a fluoroscopic diaphragm examination. The fluoroscopic diaphragm examination during deep breathing was significantly correlated with ventilator weaning and bedside spirometry parameters to assess diaphragm movement and strength. There are several methods to evaluate diaphragm movement, including ultrasonography, sonomicrometry, EMG, nuclear magnetic resonance, and video fluoroscopy [9,16-18]. The fluoroscopic diaphragm examination allows for the visualization of the entire hemi-cupula during breathing and is capable of providing a qualitative evaluation of diaphragm movement [19]. Chiodo et al. [8] argued against using a fluoroscopic diaphragm examination as a predictor of ventilator weaning. However, their study only assessed whether there was diaphragm movement and made no quantitative assessment of movement as we did in the present study. Therefore, it is difficult for us to consider that their assessment was accurate. A fluoroscopic diaphragm examination during deep breathing is very simple to perform and can objectively assess diaphragm movement, and it is an accurate method for predicting ventilator weaning.

It is well known that the incidence of respiratory complications depends on the neurologic level of patients' injuries $[16,17]$. But on the ASIA examination, anterior horn cell damage cannot be evaluated through an examination of the standard motor function above C5. A motor strength test performed in the most adjacent area or through a sensory evaluation at C3 or C4 can provide an indirect assessment. In the present study, we performed a motor examination at $\mathrm{C} 5$, which is most adjacent to the phrenic motor neurons. And we preformed sensory examinations above $\mathrm{C} 5$ and measured diaphragm movement innervated by C3, C4, and C5. Our findings show that whether or not motor and sensory functions are intact is significantly associated with diaphragm movement.

Cervical cord injuries disrupts the descending corticospinal tract originating in the cerebral cortex and bulbospinal respiratory pathway, which is the respiratory pathway from brainstem to the phrenic motor neuron located at ventral horn of the cervical spinal cord (C3C5) responsible for voluntary and automatic breathing control $[18,19]$. Taking into consideration the contiguity of both neural pathways, determining intact adjacent C5 motor function is believed to be useful in indirectly evaluating whether respiratory function is intact. Indeed, our results showed that the patient group with intact C5 motor function had significantly more movement of the diaphragm. In addition, it can be assumed that diaphragm movement would have a stronger association with intact performance on pin-prick tests, compared with the light touch test, due to the proximity of the spinothalamic and corticospinal tracts. The present study confirmed that diaphragm movement is associated with better performance on the pin-prick test than on the light touch test at more levels.

Based on the results of data analysis, three patients with neurologic injuries at the C5 level did not experience ventilator weaning, of whom two were initially assessed as having neurologic injury level at $\mathrm{C} 4$, which improved to C5. All three patients were older than 70 years. No additional factors were identified to prevent ventilator weaning; thus, despite the patients having C5-level injuries, old age may have been an influencing factor.

In our study, the variation of diaphragm movement between groups and statistical significance of the right side were more dominant than on the left side. It is well known that there is an obvious postural effect on the diaphragm movement after cervical cord injury $[20,21]$. It is believed that a patient's abdominal contents play a key role in diaphragmatic movement in the supine position as the diaphragm is aided by the weight of the abdominal contents [22]. This can be understood as similar to the important role the liver plays in diaphragmatic movement on the right side. And the right side showed much greater mobility during deep breathing than the left side. Therefore, the difference value of diaphragm movement between motor/sensory intact or impaired groups was greater on the right side, where it was more statistically significant than the left side.

There are several limitations that need to be considered in our study. First, the number of the patients is somewhat insufficient to generalize our result. However, it was meaningful to assess prospective pulmonary functions of above 60 high SCI patients. Second, the study design was cross-sectional and the times of examination of the patients were not unified. Third, the possibility of ventilator weaning was evaluated at the time the patient was 
discharged, which was not identical for each patient. Further longitudinal data to assess the significance of a physical examination and fluoroscopic diaphragm movement at equally spaced time intervals would complement our study.

In conclusion, the present study showed that rehabilitation physicians could relatively easily predict diaphragm movement and respiratory function recovery through simple bedside physical examinations, which showed significance with ventilator weaning in patients with high cervical SCI. Especially, the motor point on C5 myotome and the sensory point on $\mathrm{C} 4$ dermatome had significant correlation with fluoroscopic diaphragm movement, which helped to predict ventilator weaning. Also, these simple bedside physical examinations could determine the need for additional tests to evaluate respiratory function. Ultimately, the bedside physical examinations could provide a potential predictor to medical staff who are considering a plan to wean a patient with high cervical SCI from a ventilator or remove a T-cannula according to the patient's pulmonary function recovery.

\section{CONFLICT OF INTEREST}

No potential conflict of interest relevant to this article was reported.

\section{ACKNOWLEDGMENTS}

This work was supported by a 2-Year Research Grant of Pusan National University.

\section{REFERENCES}

1. Brown R, DiMarco AF, Hoit JD, Garshick E. Respiratory dysfunction and management in spinal cord injury. Respir Care 2006;51:853-70.

2. Galeiras Vazquez R, Rascado Sedes P, Mourelo Farina M, Montoto Marques A, Ferreiro Velasco ME. Respiratory management in the patient with spinal cord injury. Biomed Res Int 2013;2013:168757.

3. Shavelle RM, DeVivo MJ, Strauss DJ, Paculdo DR, Lammertse DP, Day SM. Long-term survival of persons ventilator dependent after spinal cord injury. J Spinal Cord Med 2006;29:511-9.

4. Jackson $A B$, Groomes TE. Incidence of respiratory complications following spinal cord injury. Arch Phys Med Rehabil 1994;75:270-5.

5. Ditunno JF Jr. Functional outcomes in spinal cord injury (SCI): quality care versus cost containment. J Spinal Cord Med 1997;20:1-7.

6. Oo T, Watt JW, Soni BM, Sett PK. Delayed diaphragm recovery in 12 patients after high cervical spinal cord injury: a retrospective review of the diaphragm status of 107 patients ventilated after acute spinal cord injury. Spinal Cord 1999;37:117-22.

7. Berlly M, Shem K. Respiratory management during the first five days after spinal cord injury. J Spinal Cord Med 2007;30:309-18.

8. Chiodo AE, Scelza W, Forchheimer M. Predictors of ventilator weaning in individuals with high cervical spinal cord injury. J Spinal Cord Med 2008;31:72-7.

9. Yi LC, Nascimento OA, Jardim JR. Reliability of an analysis method for measuring diaphragm excursion by means of direct visualization with videofluoroscopy. Arch Bronconeumol 2011;47:310-4.

10. Wicks AB, Menter RR. Long-term outlook in quadriplegic patients with initial ventilator dependency. Chest 1986;90:406-10.

11. Ditunno JF Jr, Stover SL, Freed MM, Ahn JH. Motor recovery of the upper extremities in traumatic quadriplegia: a multicenter study. Arch Phys Med Rehabil 1992;73:431-6.

12. Waters RL, Adkins RH, Yakura JS, Sie I. Motor and sensory recovery following complete tetraplegia. Arch Phys Med Rehabil 1993;74:242-7.

13. Scanlon PD, Loring SH, Pichurko BM, McCool FD, Slutsky AS, Sarkarati M, et al. Respiratory mechanics in acute quadriplegia: lung and chest wall compliance and dimensional changes during respiratory maneuvers. Am Rev Respir Dis 1989;139:615-20.

14. Urmey W, Loring S, Mead J, Slutsky AS, Sarkarati M, Rossier A, et al. Upper and lower rib cage deformation during breathing in quadriplegics. J Appl Physiol (1985) 1986;60:618-22.

15. Mortola JP, Sant'Ambrogio G. Motion of the rib cage and the abdomen in tetraplegic patients. Clin Sci Mol Med 1978;54:25-32.

16. Houston JG, Morris AD, Howie CA, Reid JL, McMillan $\mathrm{N}$. Technical report: quantitative assessment of diaphragmatic movement. A reproducible method using ultrasound. Clin Radiol 1992;46:405-7. 
17. Steier J, Jolley CJ, Seymour J, Kaul S, Luo YM, Rafferty GF, et al. Sleep-disordered breathing in unilateral diaphragm paralysis or severe weakness. Eur Respir J 2008;32:1479-87.

18. Kolar P, Neuwirth J, Sanda J, Suchanek V, Svata Z, Volejnik J, et al. Analysis of diaphragm movement during tidal breathing and during its activation while breath holding using MRI synchronized with spirometry. Physiol Res 2009;58:383-92.

19. Stephens RE, Addington WR, Miller SP, Anderson JW. Videofluoroscopy of the diaphragm during voluntary and reflex cough in humans. Am J Phys Med Rehabil 2003;82:384.

20. Chen CF, Lien IN, Wu MC. Respiratory function in patients with spinal cord injuries: effects of posture. Paraplegia 1990;28:81-6.

21. Estenne M, De Troyer A. Mechanism of the postural dependence of vital capacity in tetraplegic subjects. Am Rev Respir Dis 1987;135:367-71.

22. Maeda CJ, Baydur A, Waters RL, Adkins RH. The effect of the halovest and body position on pulmonary function in quadriplegia. J Spinal Disord 1990;3:47-51. 